Please do not remove this page

RMIT

UNIVERSITY

\title{
Speculative design and heterogeneity in indigenous nation building
}

Akama, Yoko; Keen, Seth; West, Peter

https://researchrepository.rmit.edu.au/esploro/outputs/9921860246201341/filesAndLinks?institution=61RMIT_INST\&index=null

Akama, Y., Keen, S., \& West, P. (2016). Speculative design and heterogeneity in indigenous nation building. Proceedings of the 2016 ACM Conference on Designing Interactive Systems (DIS 2016), 895-899.

https://doi.org/10.1145/2901790.2901852

Document Version: Accepted Manuscript

Published Version: https://doi.org/10.1145/2901790.2901852

Repository homepage: https://researchrepository.rmit.edu.au

Copyright is held by the owner/author(s). Publication rights licensed to ACM.

Downloaded On 2023/04/26 23:52:15 +1000 
Thank you for downloading this document from the RMIT Research Repository.

The RMIT Research Repository is an open access database showcasing the research outputs of RMIT University researchers.

RMIT Research Repository: http://researchbank.rmit.edu.au/

\section{Citation:}

Akama, Y, Keen, S and West, P 2016, 'Speculative design and heterogeneity in indigenous nation building', in Proceedings of the 2016 ACM Conference on Designing Interactive Systems (DIS 2016), Brisbane, Australia, 4-8 June 2016, pp. 895-899.

See this record in the RMIT Research Repository at:

https://researchbank.rmit.edu.au/view/rmit:38022

Version: Accepted Manuscript

Copyright Statement:

(C) Copyright is held by the owner/author(s). Publication rights licensed to ACM.

\section{Link to Published Version:}

http://dx.doi.org/10.1145/2901790.2901852 


\section{Speculative Design and Heterogeneity in Indigenous Nation Building}

\author{
Yoko Akama \\ School of Media and \\ Communication, Melbourne, \\ Australia \\ yoko.akama@rmit.edu.au
}

\author{
Seth Keen \\ School of Media and \\ Communication, Melbourne, \\ Australia \\ seth.keen@rmit.edu.au
}

\author{
Peter West \\ School of Media and \\ Communication, Melbourne, \\ Australia \\ peter.west@rmit.edu.au
}

\begin{abstract}
This paper presents a methodological exploration in postcolonial HCI. We share early insights of designing a digital platform for Indigenous nation building in Australia that speculate ways to catalyse, provoke and support necessary discussions of governance, plurality, cultural integrity and knowledge ownership. Rather than expecting consensus building or striving for problem-resolution, prototyping this digital platform has begun revealing tensions, complexities and possibilities that are significant to nation building. Manifesting and actively debating these became an epistemological pursuit for knowledge generation, but also a necessary ontological one in actively carving out 'agonistic' engagements that challenges hegemony and practice ploy-vocal future-making.
\end{abstract}

\section{Author Keywords}

Australian Indigenous nation building; Heterogeneity, Speculative design; Participatory design; Postcolonial HCI

\section{ACM Classification Keywords}

H.5.m. Information interfaces and presentation

\section{DESIGNING WITH INDIGENOUS PEOPLE}

This paper shares initial discoveries of embarking on a speculative initiative in designing a digital platform for Indigenous nation building in Australia. The authors work alongside Aboriginal and Torres Strait Islander (ATSI) researchers and participants to strategise self-determination in the absence of formal nation recognition by Australian governments. In this paper, we step into this challenging terrain to highlight how designing interactive systems can play a role in illuminating agendas and assumptions hidden from view. We aim to offer rich learning experiences and new insights that open up avenues for exploration and future-making possibilities with our partners. We build on concerns raised by many researchers in HCI like Nic

Permission to make digital or hard copies of all or part of this work for personal or classroom use is granted without fee provided that copies are not made or distributed for profit or commercial advantage and that copies bear this notice and the full citation on the first page. Copyrights for components of this work owned by others than the author(s) must be honored. Abstracting with credit is permitted. To copy otherwise, or republish, to post on servers or to redistribute to lists, requires prior specific permission and/or a fee. Request permissions from Permissions@acm.org.

DIS 2016, June 04 - 08, 2016, Brisbane, QLD, Australia

Copyright is held by the owner/author(s). Publication rights licensed to ACM. ACM 978-1-4503-4031-1/16/06 ..\$15.00

DOI: http://dx.doi.org/10.1145/2901790.2901852
Bidwell [3, 4], Margot Brereton [7] and Heike WinschiersTheophilus [26, 27] who are known for working closely and in partnership with Indigenous peoples in Australia and South Africa. These scholars report critical issues regarding culturally sensitive methods of engagement, the process of knowledge generation with Indigenous people and considerations for how the community benefits from the research. Other identified challenges include bridging knowledge systems, especially when translating local Indigenous knowledge into appropriate information and communication technologies (ICTs), which often embed Western values, logics and literacies. Whilst our paper relates to these issues, we specifically progress a discussion that foregrounds heterogeneity in emotions, values, practices, knowledge systems and ontologies to explore how engagement and participation can take place in dynamic, plural and mutually respectful ways. This is in contrast to the tendencies observed in research that sees differences as a 'deficiency' to be remedied and compensated [27] or research contorted by collective guilt about past and present wrongs to Indigenous Australians [21] that shape the discussions and relationships. How do we step into plural and contested spaces and what role can designing ICT play?

Participatory Design (PD) is a good place to start examining this question - a field of inquiry to develop methods, theory and practices that inform how design researchers actively intervene with people in social change and help transform collective futures together. PD foregrounds an ethical and political motivation for design to support, enhance and empower people in shaping their world, often bringing together heterogeneous, poly-vocal and complex constellations of users, contexts and purposes [6, 8, 16]. Moving beyond the bounded contexts of 'democracy at work', contemporary discussions are beginning to question whether consensus is possible or desirable for design researchers who wrestle with controversial 'matters of concern'. Bannon \& Ehn [8] call for on-going infrastructuring, "not necessarily to solve conflict, but to constructively deal with disagreements' [8:58]. 'Infrastructuring' builds upon Star \& Ruhleder's [23] pioneering work that observed embedded knowledge, practices and socio-material structures in organisations that are continuously built and comes into being relationally. This view and use as a verb ('-ing') shifts it from being a rigid, physical substrate like roads or power lines, to that 
which is always undergoing socio-material alignment [6, 11]. This fluid, emergent and contingent assemblage of designing contrasts with the pragmatic user-centred view that tends to dominate in HCI where participation is often seen as literal and physical participation of 'users' in designing ICT and the 'universal' way methods are reported [2]. Like Irani and colleagues' discussion on postcolonial computing [17], our designing is also partial and transculturally produced in highly specific contexts. As such, the paper is not about ATSI peoples' literal participation in technological designing. Neither is it about our team designing for them, but rather, echoing Björgvinsson and colleagues [6:43], we frame our designing as a complex socio-material process 'where various contexts or practices and technologies concurrently undergo change and therefore demand continuous infrastructuring and aligning of partly conflicting interests.' Designing as infrastructuring here builds on existing knowledge, practices and socio-material relations to consciously create ways to understand and undertake Indigenous nation building, within which we are exploring how a digital platform is playing a play a part.

Most pertinent to our discussion is Bjorgvinsson and colleagues' ideas on 'agonistic democracy' where it 'does not presuppose the possibility of consensus and rational conflict resolution, but proposes a polyphony of voices and mutually vigorous but tolerant disputes among groups' [6:48]. They see these as political acts taking place in the background of potentially challenged hegemony. Likewise, the premise of our initiative is to embrace conflicting interests and heterogeneity as a necessary process of Indigenous nation building, whilst sharpening our sensitivity and reflexivity when designing and researching.

Concerns for the loss of Indigenous knowledge, challenges of its transfer by the elders to the next generation due to migration or lack of connection have led to noteworthy benefits of ICT designs that aim to preserve, archive and disseminate indigenous knowledge and stories [see 7, 26]. While these issues are also observed in our context and could still be a by-product of our digital platform, the main emphasis of our initiative is its methodological orientation in speculative design to enable 'discursive engagement between speculation, reverie and analysis, requiring the establishment of a propositional space for ideas to be put forward, critiqued, developed' [15:89] with our ATSI partners. The speculative does not mean we are predicting future scenarios to prescribe the steps [13] for Indigenous nation building. Rather, the digital platform is a methodological inquiry to provoke, catalyse and manifest debates and propositions on what indigenous nation building is, could be and become. It invites participants to voice their fears, concerns and hopes as an integral process of nation building activity. We share our early findings, and reflections of embarking on this endeavour together.

\section{Indigenous Nation Building in Australia}

Our initiative is a component of a larger Australia Research Council funded project since 2014 to promote governance and capacity building for Indigenous communities to exercise jurisdictional power, to manage natural resources and regulate economic activity based on nation-identified goals. The framework of Indigenous Nation Building is strongly associated with political governance, as expressed by Mick Gooda, ATSI Social Justice Commissioner:

The concept of Aboriginal and Torres Strait Islander Nations is important to the identity, survival and selfdetermination of our peoples. 'Nation building' - that is, enhancing Aboriginal and Torres Strait Islander peoples' capacity for self-governance and selfdetermined economic development - is fundamental to this process' [14:112].

'Nation Building' might be a contested term to use in this context, but the definition by Gooda reinstates ATSI communities as Nations with distinct language, culture, knowledge and governing systems long before colonisation. Indigenous Nation Building thus encapsulates ways to enhance their capacity to self-govern and selfdetermine their own futures in a colonised landscape [22]. Steve Cornell and Joseph Kalt of the Harvard Project on American Indian Economic Development, designed the Nation Building framework over several decades. They assert that stable political governance and an establishment of legitimate institutions and effective governing mechanisms were significant factors in the Native nations' 'success' [10]. In the absence of constitutional recognition of ATSI peoples in Australia, the Nation Building framework, principles and methodologies are explored by three Indigenous nations in Australia - Gunditjmara, Narrindjeri and Wiradjuri. Gunditjmara and Narrindjeri nations have already created capable governance structures, processes and strategies for inter-government engagement where they are exercising decision-making authority in collaboration with, or alongside, non-indigenous governments. However, the Wiradjuri has yet to construct a formal governance structure, making it a fruitful case study to explore what Nation Building is, and could be.

Wiradjuri country is one of the largest on the Australian eastern seaboard, extending from the Great Dividing Range, bordered by the Macquarie, Lachlan and Murrumbidgee rivers in the state of New South Wales. This considerable size is a significant challenge in cohering and mobilizing a nation, further compounded by a large Wiradjuri diaspora who live 'off country' in major cities like Sydney and Melbourne. Many Wiradjuri people have experienced extensive dispersal of its citizens through forced relocation and the establishment of numerous missions. This means that Indigenous communities in Wiradjuri country are generally heterogeneous, containing a number of large regional towns with predominantly nonWiradjuri Aboriginal and non-Indigenous populations.

Indigenous knowledge and nation identities are constantly being remade in an active colonizing by Australian settler states [22]. Michael Billig's [5] seminal book on Banal Nationalism suggests how this colonialism is further reinforced and perpetuated through state structures both 
imposed and experienced through familiar material cultures we habitually touch everyday, like newspapers, money and postage stamps. This is why he calls them 'banal' and reveals how material cultures can play a role as a daily reminder of nationhood. For the authors in design, media and communication whose disciplines create, critique and make sense of such every-day material cultures, we are curious about on-line media and socio-digital spaces as emergent and liminal 'in-betweens' [1] in which to practice Indigenous sovereignty. Arguably, practices, values, aspirations, emotional dimensions, social relations and power-dynamics are invisible, fluid and vernacular. Our aim is to carve an in-between space within the existing hegemonic state to recognise, rehearse and imagine Indigenous nation building through embodied habits of daily activities, social media practices and spoken languages. We see nation building in this context that has yet to formalise through institutions and governing structures, but aspires to the same outcomes of selfdetermination and empowerment. In order to foreground the colloquial and liminal aspects of our initiative, we have used nation building (lower-case) in contrast to Nation Building (upper-case) that pursues self-governance in formal ways by the establishment of stable political governance and mechanisms.

\section{Wiradjuri nation building conversations}

In order for the research team and Indigenous partners to understand what nation building is and means for Wiradjuri, we have begun documenting various events and conversations that centred and surrounded it. These range from small and informal gatherings of ten people, to larger and formal Wiradjuri-led events of fifty people, constituted by elders, significant leaders in the Wiradjuri community as well as Indigenous and non-Indigenous people involved in tertiary education, language courses and arts practices. Some people are taking leadership in Wiradjuri nation building work and others are unfamiliar and still new to the concept. These gatherings took place at Wagga Wagga, a large urban centre on Wiradjuri country and we were invited to document and interview the participants. As we commenced our filming, rather than formally interviewing people directly from behind the camera in a confessional manner, a technique used in many 'participatory mode' documentaries [20], our approach organically evolved to become recordings of pairs or groups of people conversing with each other. We filmed dialogue already in natural flow among participants, and sometimes the conversations were framed deliberately through questions we posed. It is impossible to give detailed accounts in this short paper, so a snapshot of the breadth is given instead. Some participants spoke of the politics of being 'Aboriginal' to defy stereotype, exceed expectations and to fight as an activist; others shared their delight and empowerment of cultural renewal through language, weaving, connection to country and each other. Emotions ran high through their stories of struggle, frustration and anger of injustice but also in their hope, excitement and enjoyment of participating in cultural practices and conversations.
Heterogeneity was a constant throughout the dialogue, manifesting as tension between 'white' and 'black', or Wiradjuri and non-Indigenous conceptions. More subtly, heterogeneity was also present in those who acknowledged their Indigenous and non-Indigenous heritage; in stories of their parents that worked for and with Chinese immigrants in the local area; in personal accounts of seeing their fair skin as a bridge between the 'two worlds' of 'black' and 'white'; and how some valued various non-Indigenous partnerships and relationships as important to strengthening Wiradjuri nation.

\section{Speculating a poly-vocal digital platform}

Such conversations led our team to pursue the poly-vocal notion of 'braided voices', which aims to move away from the singular perspective of the documentary producer to one that represents the varying viewpoints of the community being recorded [12]. This approach also resonates with the way Crivellaro and colleagues [9:2854] explored poly-vocality as a methodological framework in HCI to turn the mundane and everyday talk as 'symbolic re-presentations of a social reality'. The variety of voices shaped our consideration for how the digital platform could facilitate ways in which the captured footage could be reviewed, annotated and edited by the research team and the participants. With the aim to continue discussions around the recordings, we wanted to provide the participants with the ability to categorise the material into themes and write comments about what was discussed. The prototype might look like a social media platform for video sharing but it is more than that. Figure 1 is a screen-grab of this prototype in development to speculate what could be possible if such platform was designed and made available for Wiradjuri nation building.

The left column shows un-edited footage of a conversation by a Wiradjuri language teacher, a Wiradjuri elder, a local Indigenous (non-Wiradjuri) researcher and a nonIndigenous person. The site is password protected, accessible only to researchers and the participants who can select segments that interest them as a 'clip' and tag it with keywords and comments. The right column allows viewers to see the selection of clips, tags and comments, so they can comment on the comments. This has an ethical dimension of enabling collective analysis and synthesis, thereby preventing misinterpretations or things taken out of context. It also facilitates further dialogue for us all to make sense of the broader themes and insights on nation building. This engagement through the use of 'granularity' [19] and collectively seeking out meaningful segments in combination with added meta-data, becomes a participatory action research for knowledge generation on nation building. This approach contrasts with a closed, linear documentary practice that puts forward the singular voice of the producer. It is also different to normative ways in which research participants are asked to check interview transcripts for accuracy. Instead, this prototype aims to be open for 'braided voices' to potentially continue through the ongoing contributions of further participants. 


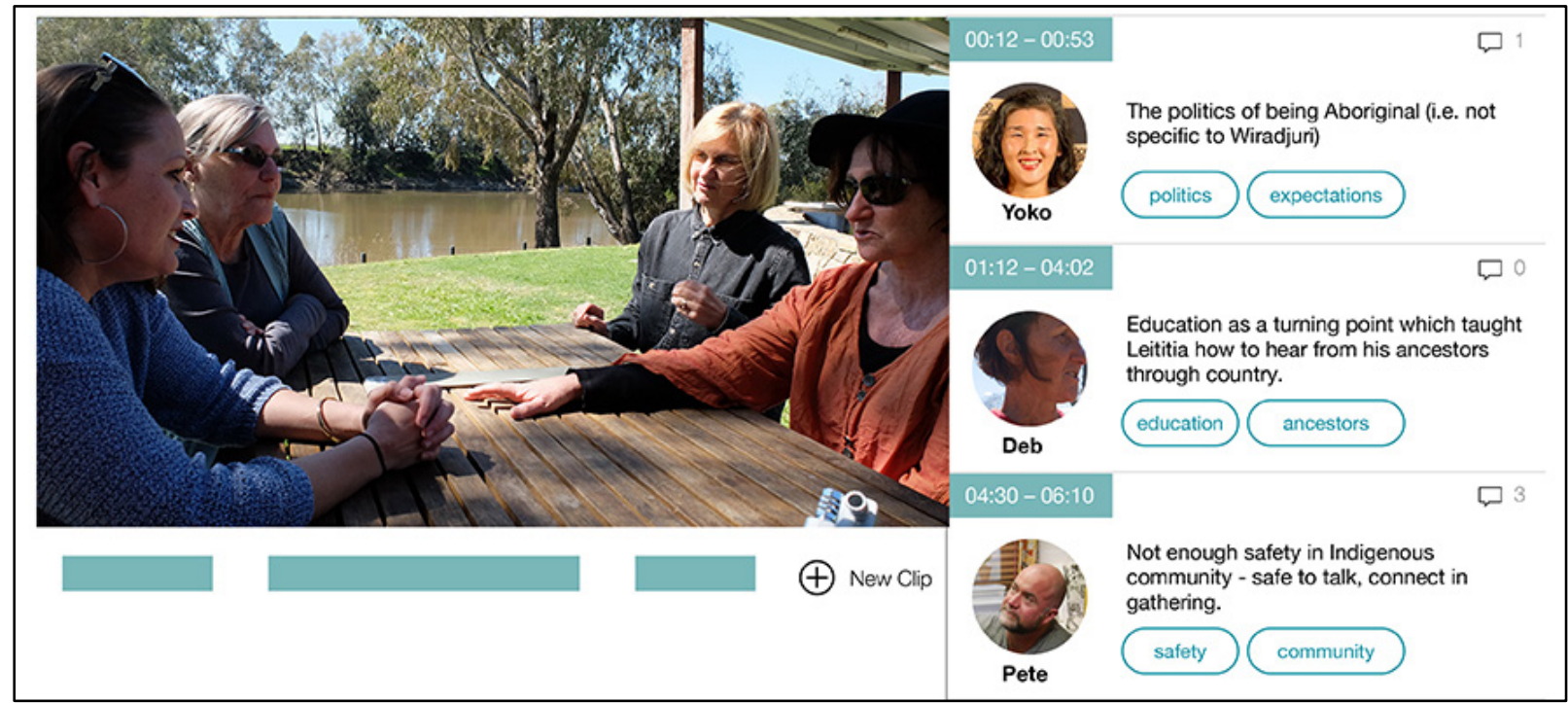

Fig. 1. A prototype for nation building digital platform

We presented this prototype as an early, evolving sketch with several participants and Wiradjuri elders to gain feedback and catalyse further conversations on nation building. Some elders raised immediate concerns - who gets to speak about Wiradjuri nation, who owns the stories - expressing concern of unfiltered, critical attacks as possible comments on the digital platform. The feedback from the elders was expected, perhaps owing to their uncertainty about digital technology and deep-seated fear for public criticism, or unfortunate impressions of researchers that have resulted from Indigenous knowledge being stolen and misappropriated before [24]. Indigenous Cultural \& Intellectual Property (ICIP) in Australia uphold rights of Indigenous peoples to protect their traditional knowledge, practices and cultures to be based on the principle of self-determination [18]. This also means that some individuals or groups have permission to speak for a particular group of people, Country and traditional knowledge, and some do not. It has been noted that age, status and gendered hierarchy can be prohibitive for some members to openly and publicly share their opinions [27]. Poly-vocality on the digital platform makes this hierarchy and cultural protocol precarious.

This highlights the contested and complex terrain of Indigenous nation building and the speculative role of designing a digital platform to provoke, manifest and crystalize issues for us all to consider. Envisaging nation building as a societal transformation necessitates consideration of those beyond the immediate group of participants we have documented. For such a large country and many Wiradjuri citizens living away in urban centres, what legitimate and meaningful ways can they connect, converse and participate in nation building? If nation building cannot happen in cultural and social isolation by Wiradjuri people alone, what are culturally appropriate ways for dialogue and decision-making?

\section{CONSIDERATIONS FOR FUTURE WORK}

Speculative design, like this digital platform, raises these questions for us all who are participating in Wiradjuri nation building to ask - it brings attention and immediacy to various dimensions that need further consideration. When formalising Indigenous Nation Building through institutions and governing structures is still uncertain, speculating how to rehearse polyvocal 'matters of concerns' can be a productive pathway. Such 'matters of concerns' can be challenging and uncomfortable for all, when past atrocities and dualisms of 'black' and 'white' are revived. When we accompany participants on a transformational experience, we as researchers are implicated in and empathising with their fears and excitement of uncertain future-making. Framing design as infrastructuring reminds us to also consider the emotional turbulence as an integral component alongside knowledge, practices and socio-material relations of nation building. The digital platform helps us speculate and be active in creating environments for slower, gentler and mindful dialogue with care, respect and cultural sensitivity.

As asserted by Irani and colleagues [17], a postcolonial view of HCI is to remove taxonomic boundaries of culture and to see it as a system of interpretive signification through which people encounter an inter-subjectively meaningful world. While the geographic borderlines of Wiradjuri nation are clear, what it means to be Wiradjuri is continuous and contingently emerging as living, dynamic practices, enacted in everyday encounters. This is richly evident in everything we have participated in and documented so far. We are designing a double-movement [25] where artifacts, like the videos and the digital platform, are in turn reconfiguring, collectively producing and intervening with cultural and relational practices. Through this designing, we envisage that our relationships will strengthen so that fears and suspicion held by some participants may transition into ways they can potentially imagine their engagement with the digital platform for us all to continue exploring Indigenous nation building.

\section{ACKNOWLEDGMENTS}

We thank our ATSI partners and participants in this study and PaperGiant team. The authors gratefully acknowledge reviewers of this paper and funding from ARC Linkage, RMIT University and University of Melbourne. 


\section{REFERENCES}

1. Akama, Yoko. 2015. Being awake to Ma: Designing in between-ness as a way of becoming with. Journal of Co-design, 11, 3-4:262-274.

2. Akama, Yoko, and Ann Light. 2012. A candour in reporting: designing dexterously for fire preparedness. In Proceedings of CHI '12, 281-290.

3. Bidwell, Nicola, and Dianna Hardy. 2009. Dilemmas in Situating Participation in Rural Ways of Saying. In Proceedings of OZCHI'09, 145-152.

4. Bidwell, Nicola, Peta-Marie Standley, Tommy George, and Vicus Steffensen. 2008. The Landscape's Apprentice: Lessons for Place-Centred Design from Grounding Documentary. In Proceedings of DIS '08, 88-98.

5. Billig, Michael. 1995. Banal Nationalism. London: Sage.

6. Björgvinsson, Erling, Pelle Ehn, and Per-Anders Hillgren. 2010. Participatory Design and Democratizing Innovation. In Proceedings of the Participatory Design Conference (PDC'10), 41-50.

7. Brereton, Margot, Paul Roe, Ronard Schroeter, and Anita Lee Hong. 2014. Beyond Ethnography: Engagement and Reciprocity as Foundations for Design Research out Here. In Proceedings of CHI '14, 1183-1186.

8. Bannon, J. Liam and Pelle Ehn. 2013. Design: design matters in Participatory Design. In Routledge International Handbook of Participatory Design, Jasper Simonsen and Toni Robertson (eds.). Routledge, London and New York, 37-63.

9. Crivellaro, Clara, Rob Comber, Martyn DadeRobertson, Simon Bowen, Peter Wright, Patrick Olivier. 2015. Contesting the City: Enacting the Political Through Digitally Supported Urban Walks. In Proceedings of CHI '15, 2853-2862.

10. Cornell, Stephen, and Miriam Jorgensen. 2007. Getting Things Done for the Nation: The Challenge of Tribal Administration. In Rebuilding Native Nations: Strategies for Governance and Development, Miriam Jorgensen (ed.). The University of Arizona Press, Tuscon, 146-172.

11. DiSalvo, Carl, Andrew Clement, and Volkmar Pipek. 2013. Communities: Participatory Design for, with and by communities. In Routledge International Handbook of Participatory Design, Jesper Simonsen and Toni Robertson (eds.) Routledge, London and New York, 182-209.

12. Fitzsimmons, Trish. 2009. Braided Channels: A Genealogy of the Voice in Documentary. Studies in Documentary Film. 3, 2:131-146.

13. Gatt, Caroline. and Tim Ingold. 2013. From Description to Correspondence: Anthropology in Real Time. In Design Anthropology, Wendy Gunn, Tom
Otto and Rachel Charlotte Smith (eds.), Bloomsbury, New York. 139-158.

14. Gooda, Mick. 2014. Social Justice and Native Title Report. Australian Human Rights Commission.

15. Grocott, Lisa. 2010. Design Research \& Reflective Practice: The facility of design-oriented research to translate practitioner insights into new understandings of design. PhD, School of Architecture and Design, RMIT University.

16. Halskov, Kim, and Nicolai Brodersen Hansen. 2015. The diversity of participatory design research practice at PDC. International Journal of Human-Computer Studies 74:81-92.

17. Irani, L., Janet Vertesi, Paul Dourish, Kavita Philip, \& Rebecca E Grinter. 2010. Postcolonial Computing: A Lens on Design and Development. In Proceedings of CHI'10,1311-1320.

18. Jenke, Terri, 2012. New Tracks: Indigenous knowledge and cultural expression and the Australian Intellectual property system. Australia Council for the Arts, Aboriginal and Torres Strait Islander Arts Board.

19. Miles, Adrian. 2005. Media Rich versus Rich Media (or Why Video in a Blog Is Not the Same as a Video Blog). In Proceedings of Blog Talk Down Under. http://incsub.org/blogtalk/?page_id=74.

20. Nichols, Bill. 2001. Introduction to Documentary. Indiana University Press, Bloomington \& Indianapolis.

21. Pedersen, Anne, Jamie Beven, Iain Walker, and Brian Griffiths. 2004. Attitudes toward Indigenous Australians: The role of empathy and guilt. Journal of Community \& Applied Social Psychology 14, 4:233249.

22. Rigney, Daryle, and Steve Hemming. 2014. Is 'Closing the Gap' Enough? Ngarrindjeri ontologies, reconciliation and caring for country. Educational Philosophy and Theory 46, 5:536-545.

23. Star, Susan Leigh, and Karen Ruhlder. 1996. Steps Toward an Ecology of Infrastructure: Design and Access for Large Information Spaces. Information Systems Research 7, 1:111-134.

24. Tuhiwai Smith, Linda. 1999. Decolonising Methodologies. (2nd. ed.) Zed Books, CPI group, UK.

25. Willis, Anne-Marie. 2006. Ontological Designing. Design Philosophy Papers. 2:1-11.

26. Winscheirs-Theophilus, Heike, Nicola Bidwell, and Edwin Blake. 2012. Altering participation through interactions and reflections in design. Co:Design: International Journal of CoCreation in Design and the Arts, 8:2-3.

27. Winschiers-Theophilus, Heike, Shilumbe ChivunoKuria, Gereon Koch Kapuire, Nicola J Bidwell, and Edwin Blake. 2010. Being Participated-A community approach. In Proceedings of PDC '10, 62-72. 